\title{
Study on the Intelligent Technology of Power Distribution Network
}

\author{
Feng Wang ${ }^{1, a^{*}}$, Jing Shi ${ }^{1, b}$, Rui Zhao ${ }^{1}$, Jinhui Liu ${ }^{1}$, Jun Liu ${ }^{1}$ and Hao Tian ${ }^{1}$ \\ ${ }^{1}$ State Grid Liaoning Electric Power Supply CO.LTD, Anshan Electric Power Supply Company, \\ Liaoning Province 114000, China \\ a astcy@126.com, ${ }^{\mathrm{b}}$ 18841231119@163.com
}

\begin{abstract}
Key words: power; distribution network; intelligent
Abstract: $10 \mathrm{kv}$ distribution networks of power energy assigned to users play part in an important role, generally conventional $10 \mathrm{kv}$ line one permanent fault will cause the whole route broke down. And we find the fault point is wasted time and energy. Recently, it's possible that run intelligent high voltage electric equipment makes the accident range smaller and realizes the whole route primary intelligence. Considering the current $10 \mathrm{kv}$ high voltage distribution lines mainly includes sub-section post, residential(or factory) district power station, RMU, cable branch box, box-type transformers, Column intelligent circuit breakers and other circuit-breaker device with control function, Take advantage of intelligent circuit breaker setting value, Selective removal of permanent failure point and uploaded information, timely analyzed and judged fault area of distribution line, pay attention to the power distribution network intelligent equipment running state of maintenance and repair, Improve the reliability of power supply to the user, it has been used as a trend and necessity.
\end{abstract}

\section{Introduction}

With the rapid development of urban distribution network, In order to meeting regional load distribution necessary, set up the sub-section post, in general sub-section post can meet remote communications functions, Vacuum circuit breaker automation control functions, Integrated automation and scheduling, monitoring by the scheduling attendant [1-3]. The disadvantage is the high costs of construction. Actually district power station formed by a power distribution station handover management of the electricity sector. Generally do not have remote communications functions, the majority in the state of unmanned unsupervised. In additional, there are also a large number of power distribution stations or cable branch box is connected to $10 \mathrm{kV}$ distribution networks, equipment level and operational level uneven [4].

Cable branch box equipment was generally arranged in the load concentrated area, the main role was for district transformer, different factories and mines to distribution of power supply, generally consisted by vacuum circuit breaker or load switch to single into and more out [5-6]. Ring network cabinet generally consisted by vacuum circuit breaker or load switch to more into and out, to achieve double power supply or multiple power supplies. Box transformer and high-low-voltage distribution cabinet formed an integrated layout, and the cover area was small. The vacuum circuit breaker of the high voltage distribution equipment was usually accompanied by the isolation switch, microcomputer protection, AC UPS or small DC power supply, construction cost is low, the vacuum circuit breaker can realize the function of microcomputer protection [7]. The disadvantage was that control power supply reliability is not high, and generally were not equipped with remote communication function.

Column circuit breaker was generally installed on the main line of the $10 \mathrm{kV}$ distribution line, the sub branch, the branch and the user interface, and conjunction used with the isolation switch. The dividing circuit breaker was mainly divided into the protection function of the surge controller and the intelligent protection function [8-9]. The inrush current controller can set the protection setting value, which did not require a special power supply, and the cost was very low. But it need to meet the current of the rated current of $40 \%$ of the working current to ensure that the current controller, the reliability was very low, belong to elimination products. The intelligent protection function of dividing circuit breaker had the function of microcomputer protection and short message communication, can realize remote mobile phone set value and mobile phone remote control and other functions, but need to 
configure the power supply to provide PT, the cost was higher than the average of the circuit breaker with the function of the current controller, was currently the primary intelligent development of distribution network is the preferred product.

\section{The distribution network intelligence was the inevitable development direction}

The difference between the traditional distribution network and the primary intelligent power distribution network was that the former occurs the line fault often causes the entire line to the large area power outage, and then the fault can be limited to a very small area, and can use its GSM SMS or GPRS and other communication functions to achieve information to inform and adjust. In order to meet the needs of national grid in five and quality service, and strive to narrow the distribution network power outage range, locate the fault point quickly had become the principal contradiction in the current quality and efficient operation of distribution network. Currently the national grid was making great efforts to improve the distribution network fault judgments and repair command efficiency, required regulatory authorities must be effective management and control of the distribution network, as soon as possible to eliminate the blind of distribution network, this also to the distribution network intelligent development opportunities. The ultimate model of the intelligent development of the distribution network would be the advanced automation of distribution network. At present, there were some urban distribution networks to achieve the distribution network dispatch automation. In this paper, we discussed the use of the existing technology and low cost equipment to reduce the accident rate and improve the power supply reliability of the distribution network primary intelligent. Further goal was to use the communication technology to realize the full realization of the distribution network TTU (with variable terminal), FTU (feeder terminal), DTU (open and close, ring network cabinet intelligent terminal), and realed power distribution network automation.

\section{The composition of the primary intelligent of transmission network}

The primary intelligent of transmission network firstly need to automatically resolve the barrier in a small range under the circumstances of the accident, increase the number of intelligent circuit breaker as much as possible in order to remove the fault in the smallest range .This requires that the intelligent vacuum circuit breaker should be installed at the branch and the user interface. At present a more realistic approach is that the type of high voltage vacuum circuit breaker on the line is intelligence .Traditional type is replaced progressively with the upgrading of rural power grids. The grid that can't be replaced in time uses short-circuit ground fault monitor. Each distribution must have the specialist who is responsible for calculating the overall breaker relay setting of each section and branch, the division, using reclosing remedy when necessary, in order to ensure selectivity. Setting debugging must be in place by the special management, line operators need to check the circuit breaker control equipment and record the corresponding operating parameters regularly. Dispatching terminal should configure the intelligent device information collection platform, and connected with the dispatch automation system.

\section{The operation and maintenance the primary intelligent of transmission network}

Compared with conventional high voltage circuit breakers of transmission network, intelligent high voltage vacuum circuit breaker supplement secondary means for controlling in order to control testing , including current transformers, control power transformer, watchdog controller, microcomputer protection devices, this is a challenge for the traditional line inspection personnel's operation maintenance .And often, whether Intelligent of power distribution lines can be used efficiently or not is related to the quality of line inspection personnel, whether Intelligent system can run safely and reliably or not is related to technical level of the operation inspection personnel. Actually most of the transmission network Patrol officers can carry out some simple basic use and operation for high voltage vacuum circuit breaker, only a few patrol officers can find the problems and defects of the 
high-voltage vacuum circuit breaker secondary system. It is imperative to improve the quality and inspection level of the power line inspection personnel. Speaking from the equipment, there are a lot of problems on relying on equipment suppliers to provide product maintenance. First of all, there is the problem of timeliness. Since the transmission network distributed in the vast remote rural areas, the transmission network can't be processed in time .But also the unity of transmission network intelligent equipment is poor, the manufacturers of transmission network intelligent equipment are too much to lead to a lot of problems, such as coexistence of a variety of device types, the number of devices is too much, software and hardware compatibility is poor. These caused some great difficulties for maintenance and spare parts ready.In addition there are some invisible faults that can't be found and eliminated in time after the completion of the distribution network of secondary equipment installation, these lead to the correct operation of smart devices is not high. For example in the use of the UPS equipment, UPS automatic shutdown after a call does not automatically re-boot, resulting in the loss of working power smart devices is not working properly. A small battery to provide operating power intelligent devices is not working due to battery depletion, some equipments simply use the AC power supply, lead to the power supply voltage dip cannot correctly off the brake when the equipment malfunction .In view of the above situation, it is suggested that the controllers with a storage capacitor are used as column intelligent vacuum breakers .energy storage capacitor can provide not less than $6 \mathrm{~S}$ to maintain the work of the intelligent controller and tripping and switch on operation . Trying to use unified product manufacturers in a dispatch area of distribution network as far as possible in order to replace and maintain. Intelligent devices in the unattended transformation and distribution room and cable branch box try to use small DC or DC panel.

\section{Practical discussion on the primary intelligence development of distribution network}

One county power supply company that author has been in uses $510 \mathrm{kV}$ urban distribution network shared lines, $3110 \mathrm{kV}$ rural distribution network shared lines, $210 \mathrm{kV}$ switching stations, 4 community substations, and over $5010 \mathrm{kV}$ branch line intelligent vacuum circuit breaker, about $40 \%$ of total installed number. In addition, over $5010 \mathrm{kV}$ user boundary intelligent circuit breaker, about $30 \%$ of total installed number, 12 HDFW and RMU, over 400 short circuit and grounding trouble indicators and over 50 box substations. Setting protection values of every intelligent breaker by coordinating with outlet settings of transformer substation has already limit about $50 \%$ area of line accident and power outages of the whole county to branch lines or user boundary area. Also, installing intelligent breakers on the branch of frequent accident area could decrease $75 \%$ power failure from line accident year on year. Besides, through checking the situation of short circuit and grounding trouble indicators, the locate efficiency of point of failure has been greatly increased. At present, there are about 20 intelligent vacuum circuit breakers having finished SMS communication function, which provide great convenience for the finding and locating of failure. As a result of $10 \mathrm{kV}$ right-of-way of the county is over 1,000 kilometers, and over $60010 \mathrm{kV}$ distribution network public-change machines and over $1,00010 \mathrm{kV}$ designed-change machines are distributed on the rural area, it's hard for inspector to solve the problem. One line transport inspection class takes charge of operations. They can only pay attention to the main line when to find the power failure and make routine maintenance, and they have no time to check branch lines and user lines often. Through statistics, over $90 \%$ line accident happens in the area of branch line and user boundary, and the failure rate happened on user boundary area is over $60 \%$, so the main contradiction of primary intelligence development of distribution network is lacking for intelligent vacuum circuit breaker on the parting place of branch lines and user boundary. County company leader pay high attention on this situation. Now the company has asked the new users who install HV circuit breakers to install demarcation intelligent breakers, and the company also take measures to phase out old and traditional circuit breakers. Uses or branch lines that have not installed intelligent breakers rely on the install of grounding trouble indicators as a remedy. The number of installing grounding trouble indicators has reached more than 400 sets. According to the current situation, it still needs a heavy investment of applying intelligent vacuum circuit breaker on distribution 
network, and to gradually achieve transmission of information, and the dispatcher automation also should increase distribution network data acquisition platform and dispatcher automation interface.

\section{Conclusion}

In a word, the focus of primary intelligence development of distribution network is to ensure uninterrupted power and reliable supplying with large amount, and to provide high quality power, good services and automatic isolation of distribution network accidents for users. From the development planning of domestic Intelligrid, the intelligence of distribution network will be the essential and important part of the whole construction of intelligrid. The main function of development of primary and intelligent distribution network is to provide good service for network terminal users: safe, stable and trustworthy power supply.

\section{References}

[1] N. Hou, The infrared thermography diagnostic technique of high-voltage electrical equipments with internal faults, in: Power System Technology, 1998. Proceedings. POWERCON'98. 1998 International Conference on, IEEE, 1998, pp. 110-115.

[2] Z. Korendo, M. Florkowski, Thermography based diagnostics of power equipment, Power Engineering Journal, 15 (2001) 33-42.

[3] F. Lizák, M. Kolcun, Improving reliability and decreasing losses of electrical system with infrared thermography, Acta Electrotechnica et Informatica, 8 (2008) 60-63.

[4] M. Clark, D. McCann, M. Forde, Application of infrared thermography to the non-destructive testing of concrete and masonry bridges, Ndt \& E International, 36 (2003) 265-275.

[5] Y. Cao, X.-m. Gu, Q. Jin, Infrared technology in the fault diagnosis of substation equipment, in: Electricity Distribution, 2008. CICED 2008. China International Conference on, IEEE, 2008, pp. 1-6.

[6] R.B. TRAYCOFF, Medical Applications of Infrared Thermography, Infrared methodology and technology, Nondestructive Testing Monographs and Tracts, 7 (1994) 469-482.

[7] C.A. Laurentys Almeida, A.P. Braga, S. Nascimento, V. Paiva, H.J. Martins, R. Torres, W.M. Caminhas, Intelligent thermographic diagnostic applied to surge arresters: a new approach, Power Delivery, IEEE Transactions on, 24 (2009) 751-757.

[8] M.A. Shafi'i, N. Hamzah, Internal fault classification using artificial neural network, in: Power Engineering and Optimization Conference (PEOCO), 2010 4th International, IEEE, 2010, pp.

352-357.

[9] J.R. Snell Jr, R.W. Spring, The new approach to prioritizing anomalies found during thermographic electrical inspections, in: AeroSense 2003, International Society for Optics and Photonics, 2003, pp. 222-230. 